\title{
A recente evolução das competências para inovar de uma empresa do setor petroquímico brasileiro: resultados positivos e limitações
}

\author{
Paulo Coutinho* \\ José Vítor Bomtempo Martins**
}

\begin{abstract}
Resumo
O sucesso do esforço de inovação tecnológica de uma empresa é função da existência não somente de uma capacitação técnica, mas também de competências organizacionais (no âmbito interno das firmas) e relacionais (no âmbito das relações entre firmas). 0 conhecimento da relação entre as competências existentes e 0 potencial de geração de resultados poderia se constituir em importante elemento na orientação das estratégias empresariais. Este trabalho busca discutir esta relação a partir da análise de como evoluíram as competências para inovar, os indicadores de desempenho e o posicionamento tecnológico de uma empresa petroquímica brasileira, desde o início da década de 1990 até hoje. 0 perfil das competências detidas pela empresa sugere que apenas suas competências técnicas aproximam-se de um nível mínimo satisfatório, o que parece ter sido comprovado pela capacidade de geração de novos produtos nos últimos anos. As competências organizacionais mostram-se ainda deficientes e exigiriam um consistente esforço da empresa, para que 0 objetivo de evoluir sua postura tecnológica possa ser atingido.
\end{abstract}

Palavras-chave: competências para inovar, posicionamento tecnológico, indústria petroquímica brasileira

\begin{abstract}
It is possible to say that the results of technology innovation efforts in a company are due not only to technical skills, but also to organizational (internal view) and relational (external view) competences. The knowledge of relations among actual competences and the potential of results generation can be an important element to the definition of corporate strategies.This work discusses these relations based on the way in which innovation competences, performance indicators and technology positioning of a Brazilian petrochemical company have evolved from the early 1990s up to 20002. It has been found that the competences (and their use) and the indicators have increased simultaneously. In some cases it was possible to identify a cause-effect relationship. It was also found that the increase in competences and their use contributed to an evolution, even though it was not intentional, of the company's technological positioning.
\end{abstract}

Key-words: competences for innovation, technological positioning, Brazilian petrochemical industry

\section{Introdução}

Nos dias de hoje, vantagens competitivas tradicionais como acesso preferencial a matérias-primas, custos de mão-de-obra e proximidade do mercado estão perdendo importância. O fator essencial de competitividade se deslocou da capacidade de produção para a capacidade inovadora. Nesse contexto, a tecnologia passou a ser considerada nos meios acadêmicos, industriais e governamentais como um dos principais fatores que trazem vantagem competitiva. Segundo Frohman (1985), a inovação tecnológica pode "criar ou destruir a lucratividade", enquanto para Maidique \& Patch (1988) é uma "força vital no ambiente competitivo da firma moderna".

\footnotetext{
* Coordenador de pesquisa e desenvolvimento da Petroflex Indústria e Comércio S. A. E-mail: pcoutinho@ petroflex.com.br. Endereço: Rua Marumbi, 600 - Campos Elíseos / Duque de Caxias-RJ CEP 25221-000

** Professor da Escola de Química, Universidade Federal do Rio de Janeiro (EQ/UFRJ). E-mail: Vitor@ eq.ufrj.br. Endereço: Escola de Química - UFRJ / Centro de Tecnologia - Bloco E - Sala 209 /llha do Fundão / Rio de Janeiro - RJ CEP:21949-900

Artigo aceito para publicação em novembro de 2004 e aceito em março de 2005.
} 
Os desafios do novo milênio tendem a reforçar ainda mais a importância do aspecto tecnológico. A globalização, a redução no ciclo de vida dos processos e produtos (GRIFFIN, 1997) e a convergência tecnológica (PRAHALAD, 1998) promovem uma constante mudança no ambiente competitivo a que as empresas estão expostas. O cenário competitivo atual faz com que as empresas convivam com ambientes organizacionais cada vez mais complexos. Isso pressiona os administradores a desenvolverem um conjunto de habilidades para lidar com as múltiplas variáveis que afetam as escolhas estratégicas das empresas. No centro dessas escolhas, de forma cada vez mais clara, está a definição de uma agenda de competências que permita a inserção competitiva da empresa, o que quase sempre corresponde a um certo nível de capacitação tecnológica e inovadora. Além disso, os resultados do esforço inovador passam a depender não só da capacitação tecnológica (competências técnicas específicas) da firma, mas também de suas competências organizacionais (no âmbito interno da firma) e relacionais (no âmbito das relações entre firmas).

As pesquisas mais recentes centram o problema da inovação na construção de competências adequadas. Entretanto, deve-se admitir certa dificuldade em identificar e caracterizar tais competências. Mais problemático ainda seria relacioná-las com o posicionamento tecnológico atual das empresas e as perspectivas futuras. Essa dificuldade afetaria particularmente empresas de países em desenvolvimento, onde a industrialização começou com a aquisição de tecnologias externas já consolidadas. Com o conhecimento obtido, partiu-se para a diferenciação de processos e produtos. O próximo passo seria o início do desenvolvimento de processos e produtos totalmente originais (KIM, 1999). A partir daí, a questão que se coloca é saber se as empresas precisam aprimorar sua capacitação e como prepará-las para passar de um estágio a outro, uma vez que seus recursos são geralmente escassos. Em outras palavras, que nível de competências a empresa detém e que agenda de desenvolvimento de novas competências pode ser sugerida?

Este artigo propõe uma metodologia para identificar as competências existentes e sua evolução na firma. Toma como ponto de partida o estudo de François (1999), em que é proposto um questionário para avaliar se existem competências que identifiquem e implementem a inovação numa firma. Compreendem competências de caráter geral que todas as firmas inovadoras deveriam buscar. O questionário proposto por François (1999) foi modificado, para atender as necessidades deste artigo, cujo objetivo é não só avaliar a existência ou não dessa competência, mas também seu nível de desenvolvimento na empresa. Foi proposto ainda um novo conjunto de competências, o das competências técnicas específicas. Essas competências são próprias da firma e das indústrias com as quais ela compete, ao mesmo tempo que têm estreita ligação com os conhecimentos específicos relacionados aos seus produtos e processos.

Com base na identificação do nível atual de desenvolvimento das competências na firma e a partir da identificação do seu posicionamento tecnológico é possível sugerir, a partir da utilização da metodologia proposta, uma agenda de aquisição de competências, tendo em vista os objetivos da empresa. A metodologia é aplicada em uma empresa petroquímica brasileira, a Petroflex Indústria e Comércio S.A.

\section{A visão das firmas com base na noção de competências e seu posicionamento tecnológico}

O campo de estudo aberto pela abordagem da firma baseada em recursos (resource based view - RBV), que propõe a valorização dos atributos internos da empresa como fonte de vantagem competitiva sustentável, tem suas raízes em Penrose (1959). Da perspectiva de Penrose, as firmas são vistas como um conjunto de recursos que estão na base das estratégias de crescimento lançadas pelos empreendedores. Apesar desses conceitos terem sido propostos no final da década de 1950, foi apenas em meados dos anos 1980 que foram efetivamente vistos como uma alternativa estratégica para as empresas. Inicialmente, Nelson \& Winter (1982) propuseram uma visão evolucionista, que influenciou todo o pensamento neo-schumpeteriano, revalorizando a contribuição de Penrose. Um dos primeiros estudos a adotar a expressão resource based view (RBV) foi o de Wernerfelt (1984). Em seu artigo, ele faz um paralelo entre a visão tradicional baseada em produtos e a visão baseada em recursos, mostrando que neste caso novas perspectivas estratégicas podem ser vislumbradas, principalmente, para firmas que pretendam diversificar suas atividades para outros mercados. Não há uma preocupação em definir formalmente o que sejam os recursos, mas torna-se claro que, além dos ativos tangíveis já citados por 
Penrose (1959), o autor considera também os ativos intangíveis, principalmente, pela ênfase dada à tecnologia como um importante fator na estratégia da empresa.

No início da década de 1990, novos estudos no âmbito da RBV foram publicados. A noção acabou por ser incorporada ao próprio vocabulário dos administradores e dirigentes, a partir de Hamel \& Prahalad (1990, 1995). Esses autores desenvolveram a idéia de competência essencial, hoje amplamente difundida e, de certa forma, banalizada. Apesar da grande aceitação da abordagem RBV, ainda hoje há uma grande discussão em torno dos termos e conceitos adotados ao longo do tempo por diferentes autores. Ainda não há um consenso sobre o que seja considerado um recurso da firma, pois alguns autores se baseiam numa visão mais restrita, como Penrose (1959) e Wernerfelt (1984), enquanto outros consideram um conceito mais amplo, como Barney (1996).

Collis \& Montgomery (1995) incluíram a análise do ambiente externo no conceito de RBV, ao afirmarem que os recursos não poderiam ser avaliados isoladamente, uma vez que o seu valor seria determinado a partir da interação com as forças de mercado. Teece et al. (1997), preocupados com a sustentabilidade das vantagens competitivas baseadas nos recursos da firma, propuseram o conceito de "capacidades dinâmicas" (dynamic capabilities). O termo dinâmico se refere à capacidade da firma de renovar competências para enfrentar as mudanças no ambiente de negócios. As "capacidades dinâmicas" são de certa forma "capacidades motrizes", que renovam as vantagens competitivas das empresas nos ambientes dinâmicos. Neste artigo, os termos "competências" e "capacidades" são usados indistintamente, como sinônimos.

\subsection{As competências de uma firma para inovar}

A identificação dos recursos que serão fonte de vantagem competitiva não é tarefa simples, pois muitas das características que lhes são atribuídas só podem percebidas intuitivamente. Como definição geral, um recurso valioso deve contribuir para a produção de algo que os clientes desejem, a um preço que estejam dispostos a pagar. Além disso, o recurso só proporciona uma efetiva vantagem competitiva se for singular e de difícil imitação (COLLIS \& MONTGOMERY, 1995).

A abordagem da firma com base nas competências leva ao entendimento de que o esforço de inovação implica naturalmente não só capacitação tecnológica, mas também competências organizacionais (no âmbito interno das firmas) e relacionais (no âmbito das relações entre firmas). É importante explicar o que se entende aqui por competências tecnológicas, organizacionais e relacionais.

A capacitação tecnológica compreende tanto a existência de competências técnicas específicas quanto de competências técnicas de caráter mais geral, associadas à capacidade de identificação e implementação das inovações. As competências de caráter mais geral são competências de uma firma inovadora, independente da indústria a que pertence. Por sua vez, as competências técnicas específicas estão relacionadas com a capacidade da firma de gerar, adquirir e internalizar novos conhecimentos. Estes devem levar a produtos, processos ou aplicações que sejam novos para a empresa, não necessariamente para o mercado. São competências próprias da firma e das indústrias com as quais compete.

As competências organizacionais e relacionais também compõem o conjunto de competências para identificação e implementação da inovação. Referem-se à capacidade da empresa de fazer com que o conhecimento existente se transforme efetivamente em novos processos, produtos ou aplicações, contribuindo para os seus resultados.

Entretanto, se a noção de competências é bastante rica e apropriada para compreender a dinâmica da inovação em um cenário voltado para a aprendizagem e criação de conhecimento, parece-nos que ainda é problemático identificar com exatidão as competências nas empresas e que utilização gerencial podem ter. Este artigo pretende contribuir para uma melhor compreensão das competências para inovar nas empresas industriais no Brasil.

Como ponto de partida, são tomadas as proposições de François (1999), visando avaliar as competências para inovar, vistas aqui como competências de identificação e implementação. A essas competências de caráter mais 
geral associam-se competências técnicas específicas, identificadas a partir da proposição de Coutinho (2004). Para isso, foi desenvolvido um roadmap que, com a participação de todos os profissionais (gerentes, chefes, engenheiros etc.) das áreas de pesquisa e desenvolvimento ( $\mathrm{P} \& \mathrm{D})$, produção e de marketing, permite o desdobramento dos produtos e processos em competências técnicas específicas. Assim, são identificados os pontos fortes e fracos dos seus produtos e processos, que deveriam ser o foco do processo de melhoria contínua da empresa.

Para François (1999), as competências são vistas como pertencentes à empresa. Aqui, a abordagem está voltada para a inovação como uma finalidade. O ponto central é o questionamento sobre as aptidões que a priori uma firma deve ter para que haja inovação e para que esta seja rentável. Essa concepção é coerente com as proposições de Nelson \& Winter (1982) e de Teece et al. (1997), que destacam a existência de rotinas para inovar (ou rotinas organizacionais) como base de atuação das empresas diante da competição.

François (1999) discute diversas propostas de questionários visando identificar as competências das empresas e avaliar em que grau essas competências estão efetivamente implantadas como "rotinas para inovação". Abordagem similar é feita por Burgelman et al. (1995), que apresentam um check list para avaliar se a firma tem ou não os atributos necessários para inovar.

Este artigo adota, por sua simplicidade e facilidade operacional, a proposta que em François (1999) é denominada de "questionário de competências". 1 O questionário limita-se exclusivamente a perguntar aos responsáveis se consideram que suas empresas têm uma lista de competências previamente definidas como base para inovação. Na versão desenvolvida para esta pesquisa, os responsáveis também avaliam o grau de consolidação dessas competências nas empresas, atribuindo um grau de zero a cinco para cada uma delas. Naturalmente, pode-se discutir o grau de subjetividade com que cada responsável julga se sua empresa tem ou não (e em que nível) determinada competência. O questionário parte do princípio de que as competências seriam transversais e envolveriam, de certa forma, todas as atividades da empresa, não sendo portanto funcionais.

O questionário em questão, apresentado no Anexo 1, tem 68 perguntas que envolvem o mesmo número de competências elementares. Para efeito de análise, essas competências podem ser agrupadas de duas formas distintas: por grupos de competências complexas ou pela natureza das competências. Foram considerados os seguintes grupos temáticos de competências complexas:

- inserção da inovação na estratégia corporativa;

- acompanhamento, prevenção e atuação na evolução dos mercados;

- desenvolvimento das inovações;

- organização e direção da produção de conhecimento;

- apropriação e absorção das tecnologias externas;

- gestão e defesa da propriedade intelectual;

- gestão dos recursos humanos, de uma perspectiva inovadora;

- financiamento da inovação e

- venda da inovação.

Entretanto, a análise com base nos grupos evidencia que um mesmo grupo compreende competências de natureza diversa. O "Desenvolvimento das inovações", por exemplo, depende tanto de competências voltadas para o favorecimento do trabalho em equipe quanto da capacidade de adquirir rapidamente equipamentos e insumos tecnologicamente novos. Foi proposto, então, uma segunda forma de análise, a partir da natureza das

\footnotetext{
${ }^{1}$ Um questionário desse tipo foi utilizado em pesquisa realizada pelo Ministério da Indústria da França, em 1997.
} 
competências. Foi adotada, então, a proposição de Munier (1999), que classifica as competências em organizacionais, relacionais, técnicas e de meios.

As competências organizacionais são as que favorecem a criação de novos conhecimentos. Inclui as que dizem respeito à gestão dos recursos humanos e as relacionadas à inovação em uma dimensão transversal no interior da firma. Segundo Munier (1999), elas poderiam ser subdivididas em três grupos. O primeiro seria formado pelas competências que favorecem a criação de novos conhecimentos, dando importância às interações entre os indivíduos e sua autonomia. O segundo englobaria as competências que favorecem a dimensão transversal da inovação, e o terceiro seria formado pelas competências de identificação e avaliação do saber individual e coletivo.

As competências relacionais são as que atuam nos mercados (relações com a concorrência e com a demanda) e aquelas relacionadas com a capacidade da empresa de cooperar, formar alianças e se apropriar de tecnologias externas.

As competências técnicas são aquelas relacionadas com a gestão da produção e das tecnologias, essencialmente, dentro da firma. Essas competências técnicas, genéricas para uma firma inovadora, estão voltadas para a identificação e implementação de inovações. Elas se distinguem, como explicado anteriormente, do conhecimento técnico específico da firma. Este corresponde ao que se denominou "competência técnica especifica" e foi identificado com base no roadmap proposto por Coutinho (2004).

As competências ditas de "meios" são as que permitem à empresa desenvolver pesquisa e desenvolvimento, além de obter financiamentos e/ou vender a inovação. São as competências que possibilitam à empresa mobilizar recursos para desenvolver uma inovação e sua capacidade de arcar com os custos que resultam desse desenvolvimento.

Os resultados da pesquisa são apresentados para ambos os agrupamentos propostos. $\mathrm{Na}$ análise e discussão privilegiou-se a segmentação baseada na proposta de Munier (1999), destacando-se, em alguns casos, alguns grupos de competências complexas consideradas de particular importância para a indústria petroquímica.

\subsection{0 posicionamento tecnológico}

Os recursos escassos e a natureza cumulativa do know-how tecnológico enfatizam a necessidade da empresa definir uma estratégia capaz de ampliar o conteúdo das tecnologias existentes e de acessar e absorver tecnologias emergentes a um custo mínimo. A estratégia tecnológica tornou-se um ingrediente central no conceito da empresa, e a tecnologia passou a constituir uma das bases do planejamento estratégico, orientando a questão fundamental de como estabelecer uma vantagem competitiva e de como garantir a sobrevivência da firma. Com isso, as estratégias de negócios e de tecnologia passam a ser cada vez mais interdependentes, enquanto a formulação da estratégia tecnológica passa a ter que considerar aspectos internos e externos à firma.

Isso faz com que as empresas não estejam totalmente livres para definir suas estratégias tecnológicas. Para simplificar a questão, buscou-se aqui identificar pesquisas que pudessem orientar os administradores quanto às restrições aí existentes. No aspecto externo, os estudos de Pavitt (1990), Burgelman et al. (1995) e Malerba \& Orsenigo (1993) identificam explicitamente as questões a serem avaliadas na construção da estratégia tecnológica da empresa. No aspecto interno, é adotada a proposta de Coutinho et al. (2004), a qual pressupõe que a capacidade de inovação de uma firma depende de sua posição em um modelo evolutivo.

Para Pavitt (1990), as oportunidades inovadoras abertas para a firma e certas decisões estratégicas - como, escolhas entre domínio tecnológico amplo ou focalizado, orientação para produto ou processo, ou mesmo a opção entre ser pioneira ou seguidora - estariam condicionadas pelo seu tamanho e por seu core business. Dessa forma, suas estratégias seriam determinadas por suas trajetórias de mudança tecnológica, conforme Pavitt et al. (1989) e Pavitt (1990). Pavitt (1990) identificou categorias distintas de indústrias baseadas nessa trajetória de mudança: dominadas pelos fornecedores, intensivas em escala, intensivas em informação, fornecedoras especializadas e science based. 
Conforme Burgelman et al (1995), a estrutura da indústria, o regime de apropriabilidade, a disponibilidade ou indisponibilidade de ativos complementares, o surgimento do projeto dominante e o grau de rivalidade também influenciariam a estratégia tecnológica das empresas.

Malerba \& Orsenigo (1993) definiram regimes tecnológicos com base nas condições existentes de oportunidade, apropriabilidade, cumulatividade da mudança tecnológica e complexidade do conhecimento básico. A partir dessa definição estudaram a relação entre o comportamento das firmas e os regimes tecnológicos a que estavam expostas. A condição de oportunidade refletiria a facilidade de inovar, levando em conta uma determinada quantia investida em pesquisa. A condição de apropriabilidade responderia pela possibilidade de proteger a inovação de imitadores e assim ter lucro a partir dessa atividade. Conforme Chiesa \& Manzini (1998), a apropriabilidade de uma inovação poderia ser medida pelo esforço que os competidores fazem para reduzir ou remover a vantagem criada a partir de uma dada inovação. A cumulatividade representaria o fato de que a atividade inovadora e a inovação de hoje formam a base de construção da inovação de amanhã, e que são as firmas inovadoras de hoje que estariam mais propensas a inovar no futuro.

Segundo Malerba \& Orsenigo (1993), os regimes tecnológicos moldam o leque de comportamentos viáveis da firma, em termos de estratégia tecnológica básica e tipo de organização. Esses regimes definem prescrições e trade-offs capazes de orientar as empresas na busca da atuação mais viável. Definem ainda as alternativas de estratégias tecnológicas existentes. As dimensões da atividade de inovação estariam diretamente relacionadas com as oportunidades tecnológicas existentes e com o grau de cumulatividade da mudança no ambiente. De forma inversa, a atividade de inovação se reduz, à medida que cresce o grau de apropriabilidade e mais complexo se torna o conhecimento básico.

Malerba \& Orsenigo (1993) propuseram ainda que existiriam algumas características (com respeito a preços relativos e mecanismos de incentivo) de aprendizado e acumulação de conhecimento que afetam a taxa e a estrutura da atividade de inovação, e que essas características seriam diferentes entre as indústrias. Para eles, o padrão específico de atividade inovadora de um setor poderia ser explicado como resultante do regime tecnológico a que está exposto.

A literatura apresenta diversas tipologias para a postura tecnológica das empresas (MILLER, 1988; ADLER, 1989). De modo geral, essas tipologias se baseiam em dimensões de marketing, de estratégia de inovação ou de estratégia competitiva. Coutinho et al. (2004) propuseram uma análise com base em uma dimensão evolutiva. Essa abordagem parece adequada para os objetivos deste artigo, pois pressupõe que a empresa pode evoluir por esse modelo, a partir do crescimento de suas competências para inovar.

Nesse modelo, as empresas são classificadas como pioneiras ou seguidoras, conforme seu estágio evolutivo. Empresas pioneiras são aquelas que têm como foco estratégico a busca de inovações radicais nas indústrias com as quais competem; ou seja, procuram levar ao mercado produtos e processos totalmente originais. Podem ser citados como casos clássicos de pioneirismo (FOSTER, 1986): P\&G (fraldas Pampers), Michelin (pneus radiais), Johnson \& Johnson (Tylenol) e U. S. Surgical (grampos para sutura).

Empresas seguidoras são aquelas que têm como foco inovações incrementais, tendo como estratégia básica inicial a imitação. Buscam posteriormente alguma diferenciação para seus produtos. Podem ser classificadas como seguidoras rápidas e lentas. As seguidoras rápidas podem ser proativas ou reativas. As seguidoras lentas se limitam a imitar ou comprar tecnologias disponíveis no mercado. Normalmente, essas empresas não fazem investimentos significativos em pesquisa e desenvolvimento, limitando-se, quando o fazem, à pesquisa e desenvolvimento incremental de processo. Por meio de licenciamento ou parcerias de diversos tipos, buscam no mercado a tecnologia de que necessitam.

As seguidoras proativas inovam lançando produtos que, apesar de adotarem a mesma base tecnológica lançada pela pioneira, apresentam vantagens percebidas pelo cliente, o que possibilita uma elevação na margem apropriada pela seguidora. Essa inovação pode se dar pela agregação de mais tecnologia, pela geração de produtos modificados e direcionados para atender nichos específicos de mercado, pelo uso de vantagens competitivas próprias (como acesso ou desenvolvimento de matérias-primas alternativas de baixo custo, 
logística de mercado etc.) ou, simplesmente, através de artifícios de marketing. De um modo geral, a vantagem temporária da seguidora proativa vai durar o tempo necessário para que pioneiros e seguidores reativos consigam reproduzir as condições aí criadas. O caso do scanner CAT e do MRI da GE Medical seriam exemplos de inovações desenvolvidas segundo uma estratégia de seguidora proativa (MORONE, 1993).

Por sua vez, a estratégia da seguidora reativa também se baseia na busca da diferenciação do produto, mas a partir de orientação ou da solicitação do cliente. Por esse motivo, da mesma forma que a imitadora, costuma contribuir para reduzir o valor de um determinado produto no mercado. Na verdade, na maior parte das vezes, atua em resposta à demanda de compradores que buscam um segundo ou terceiro fornecedor para baixarem os preços de seus insumos. A seguidora reativa procura, assim, aprender com os erros da pioneira e acompanhar de perto a proativa, investindo sempre em soluções já consagradas.

As seguidoras lentas ou imitadoras trabalham com processos e produtos já consolidados, cuja tecnologia já não é estratégica para o seu criador ou já está completamente difundida pelo mercado. Buscam a minimização do custo operacional (produção, overheads etc.), tendo escala e automação como fontes principais de vantagem competitiva. A postura da seguidora costuma ser o primeiro estágio na evolução das empresas de países em desenvolvimento.

Essa tipologia tem a vantagem de poder ser relacionada com a trajetória de evolução tecnológica das empresas. À medida que ganham experiência de produção, conhecem o mercado em que atuam e se capacitam tecnologicamente, as empresas podem galgar etapas, passando de imitadoras a seguidoras, de seguidoras reativas a proativas e, por fim, a pioneiras. Há aqui uma clara associação com as idéias apresentadas por Kim (1999).

A identificação das competências necessárias para passar de um estágio a outro constitui etapa fundamental na orientação estratégica a ser adotada pela empresa na busca de uma vantagem competitiva que lhe assegure sustentabilidade no mercado.

Galgar etapas no processo evolutivo pressupõe, a princípio, uma evolução em todas as competências para inovar. No entanto, é possível perceber que determinadas competências são típicas de cada um dos estágios de postura tecnológica propostos.

A Tabela 1 apresenta alguns requisitos típicos de cada um dos estágios de posicionamento tecnológico propostos. 
Tabela 1

Requisitos típicos para as diferentes estratégias de postura tecnológica

\begin{tabular}{|c|c|c|c|c|c|}
\hline & $\begin{array}{l}\text { Intensidade e } \\
\text { tipo de P\&D }\end{array}$ & Produção & Marketing & Organização & Competências \\
\hline Pioneiro & $\begin{array}{l}\text { Requer P\&D no } \\
\text { estado da arte; }\end{array}$ & $\begin{array}{l}\text { Flexibilidade } \\
\text { operacional, } \\
\text { escopo }\end{array}$ & $\begin{array}{l}\text { Abertura de } \\
\text { mercados }\end{array}$ & Flexibilidade & $\begin{array}{l}\text { Propriedade intelectual, } \\
\text { prospecção tecnológica, } \\
\text { clima propício a } \\
\text { inovação, parcerias } \\
\text { inclusive com } \\
\text { concorrentes }\end{array}$ \\
\hline $\begin{array}{l}\text { Seguidor } \\
\text { proativo }\end{array}$ & $\begin{array}{l}\text { P\&D } \\
\text { incremental de } \\
\text { processo / } \\
\text { produto, algum } \\
\text { P\&D radical / } \\
\text { fundamental }\end{array}$ & $\begin{array}{l}\text { Flexibilidade } \\
\text { operacional, } \\
\text { escopo > } \\
\text { escala }\end{array}$ & $\begin{array}{l}\text { Diferenciação e } \\
\text { busca de nichos } \\
\text { de mercado }\end{array}$ & $\begin{array}{l}\text { Flexibilidade > } \\
\text { eficiência }\end{array}$ & $\begin{array}{l}\text { Estruturação em torno } \\
\text { dos projetos, conheci- } \\
\text { mento das necessidades } \\
\text { da cadeia, parcerias com } \\
\text { clientes e instituições de } \\
\text { pesquisa }\end{array}$ \\
\hline $\begin{array}{l}\text { Seguidor } \\
\text { reativo }\end{array}$ & $\begin{array}{l}\text { P\&D } \\
\text { incremental de } \\
\text { processo }\end{array}$ & $\begin{array}{l}\text { Escala > } \\
\text { escopo, } \\
\text { minimizar } \\
\text { custo }\end{array}$ & Diferenciação & $\begin{array}{l}\text { Eficiência > } \\
\text { flexibilidade }\end{array}$ & $\begin{array}{l}\text { Aproximação com } \\
\text { cliente, } \\
\text { acompanhamento da } \\
\text { evolução do mercado } \\
\text { identificação das } \\
\text { competências existentes }\end{array}$ \\
\hline $\begin{array}{l}\text { Imitador / } \\
\text { comprador }\end{array}$ & $\begin{array}{l}\mathrm{P} \& \mathrm{D} \\
\text { inexistente }\end{array}$ & $\begin{array}{l}\text { Escala; } \\
\text { minimização } \\
\text { de custos }\end{array}$ & $\begin{array}{l}\text { Minimização de } \\
\text { custos } \\
\text { industriais e } \\
\text { despesas } \\
\text { comerciais }\end{array}$ & $\begin{array}{l}\text { Eficiência e } \\
\text { rígido controle }\end{array}$ & $\begin{array}{l}\text { Qualidade e eficácia na } \\
\text { produção, rapidez na } \\
\text { aquisição de } \\
\text { equipamentos e de } \\
\text { insumos novos }\end{array}$ \\
\hline
\end{tabular}

Fonte: Coutinho (2004)

\section{Metodologia}

Este estudo aborda a indústria petroquímica brasileira e uma empresa do setor, a Petroflex Indústria e Comércio S.A. A pesquisa foi feita a partir de um questionário (Anexo 1) e de entrevistas semi-estruturadas.

As empresas do setor foram selecionadas levando-se em conta seu grau de importância na indústria petroquímica brasileira. Com base nos anuários da Associação Brasileira da Indústria Química (Abiquim), o questionário foi enviado para as 12 maiores empresas de capital nacional do setor, das quais, 10 responderam. Essas 10 empresas representam mais de $90 \%$ do faturamento da amostra e $75 \%$ de toda a indústria petroquímica, considerando-se as empresas de controle estrangeiro. As respostas incluem produtores de petroquímicos básicos, intermediários e produtos finais, representando os diversos papéis que as empresas dessa indústria exercem na cadeia produtiva.

Foram escolhidos como respondentes os responsáveis diretos pela implementação da política de pesquisa e desenvolvimento das empresas. O pressuposto foi o de que, em face das características tecnológicas das empresas estudadas, a direção de $\mathrm{P} \& \mathrm{D}$ teria uma visão geral da inovação nas empresas. Entretanto, pela diversidade de cultura e de estruturas organizacionais encontradas, a pesquisa envolveu pessoas de diferentes níveis hierárquicos, incluindo diretores, gerentes e coordenadores de área.

O envio e a coleta das respostas foi personalizado, ocorrendo em duas etapas. Inicialmente, o questionário era entregue após um primeiro contato, no qual os objetivos da pesquisa e os principais conceitos utilizados eram apresentados e discutidos. Os representantes das empresas ficavam com o material para posterior envio das respostas. Recebidas e analisadas as respostas, era feito um novo contato (pessoalmente ou por telefone) para esclarecer dúvidas e corrigir eventuais contradições encontradas. 
Para avaliar a aplicação dos conceitos aqui definidos, foi escolhida a Petroflex Indústria e Comércio S. A.. Os processos utilizados, o portfólio de produtos, a abertura do mercado brasileiro (que acabava com um quase monopólio de mais de 25 anos) e a sua privatização em 1992 criavam um cenário particularmente interessante para aplicação da metodologia aqui proposta. Além disso, a partir das entrevistas realizadas no estudo de Coutinho et al. (2004), verificou-se que os entrevistados identificavam posicionamentos tecnológicos distintos da empresa no período entre 1992 e os dias de hoje. Isso era particularmente interessante, pois permitia avaliar a evolução das competências internas relacionadas com a evolução do posicionamento.

Buscou-se identificar as competências existentes e como a empresa geriu os aspectos ligados à estratégia tecnológica desde a sua privatização até hoje. Isso foi determinado a partir dos questionários e entrevistas semiestruturadas com representantes das áreas de $\mathrm{P} \& \mathrm{D}$, produção, comercial e financeira, incluídos os diretores superintendentes e gerentes técnicos do período. Procurou-se ainda, junto às áreas técnicas, levantar quais seriam e como evoluíram as competências técnicas específicas da empresa.

Foram realizadas cerca de 19 entrevistas. Os entrevistados foram deixados à vontade, para não opinar em assuntos que porventura não fossem do seu conhecimento. Dessa forma, algumas das questões não têm o mesmo número de respostas.

\section{A Petroflex Indústria e Comércio S.A.}

Em 4-3-1962 entrava em operação, em Duque de Caxias (RJ), como uma unidade operacional da Petrobras, a Fabor - Fábrica de Borracha. Com capacidade inicial para produzir 40.000t/ano de borrachas de estireno e butadieno em emulsão (ESBR), sofreu ao longo dos anos diversas ampliações a partir da assimilação da tecnologia adquirida do consórcio Goodyear-Firestone. Em março de 1968, a Fabor foi incorporada à Petroquisa, recém-criada holding petroquímica do grupo Petrobras. Em 1971, entrava em operação uma unidade para produção de látex sintético de estireno e butadieno (látex de SBR), com capacidade para 4.500t/ano e tecnologia adquirida da International Synthetic Rubber.

Denominada Petroflex a partir de 1977, em 1985 inaugurava, no Rio Grande do Sul, uma segunda fábrica de SBR, com capacidade inicial de 40.000t/ano e tecnologia totalmente nacional. No mesmo ano, entrava em operação em Duque de Caxias, uma unidade para produção de polibutadieno líquido hidroxilado (PBLH), com capacidade para 1.000t/ano, cuja tecnologia fora desenvolvida juntamente com o Centro de Pesquisas da Petrobras (Cenpes). Ao ser privatizada em 1992, sua capacidade era de cerca de 200.000t/ano e produzia apenas ESBR, Polibutadieno líquido (PBLH) e látex de SBR.

Com uma parcela considerável de suas vendas direcionadas às poucas empresas do setor de pneumáticos e recauchutagem, em sua maioria multinacionais com amplo acesso ao mercado exterior, a companhia viu, a partir de meados da década de 1990, suas margens serem comprimidas gerando um quadro financeiro e operacional desfavorável, conforme pode ser visto na Figura 1.

Para melhorar sua situação a Petroflex, a partir de 1997, começou a buscar o desenvolvimento e a produção de elastômeros de maior valor agregado. Esses elastômeros deveriam ser produzidos em unidades já existentes, aproveitando a capacidade ociosa, uma vez que os problemas de caixa da empresa não permitiam grandes investimentos. Esses produtos deveriam envolver tecnologias em sinergia com aquelas já dominadas pela empresa, visto que deveriam aproveitar as bases industriais existentes. 
Evolução do lucro líquido e do EBITDA* da Petroflex (US\$ milhões)

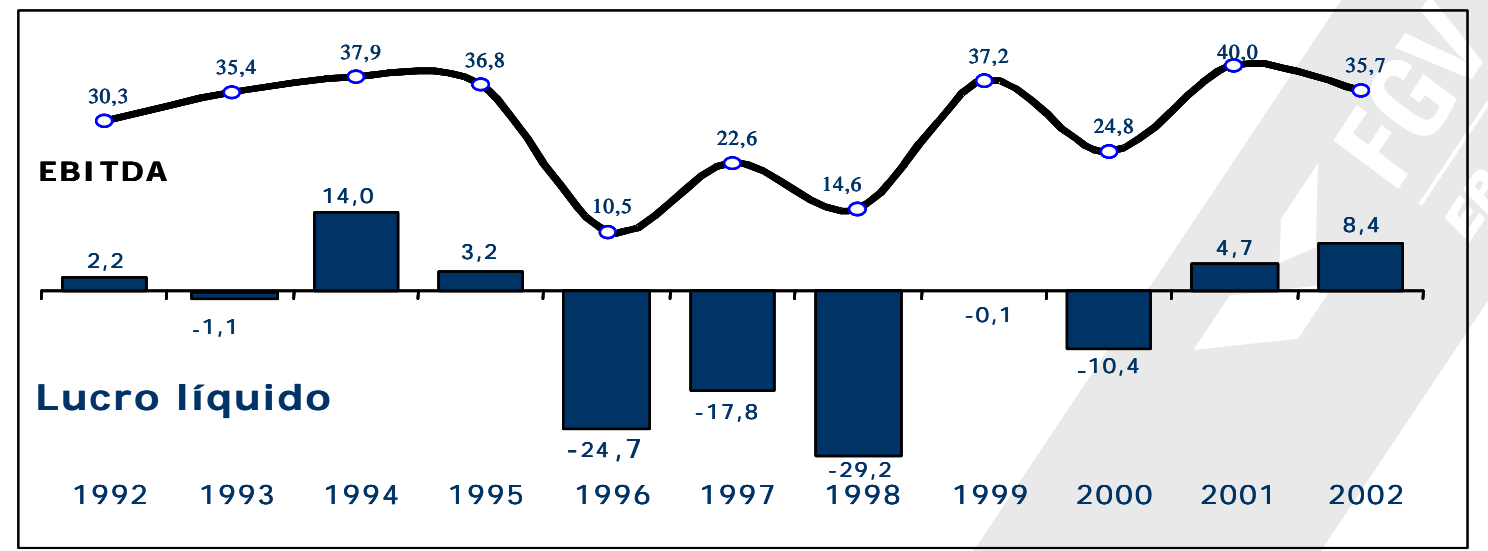

Fonte: Relatórios internos da Petroflex.

* EBITDA, earnings before interest, taxes, depretiaion and amortization (lucro antes dos juros, impostos, depreciação e amortização)

Desde então foi desenvolvido um grande número de produtos para os mais diversos segmentos de mercado. Paralelamente, a empresa tinha forte atuação nos processos já utilizados em seus parques fabris, buscando reduzir as perdas, aumentar a confiabilidade operacional e diminuir o passivo ambiental existente. Hoje, a Petroflex é a maior empresa latina americana no seu segmento e está entre os dez maiores produtores mundiais de borracha sintética. Além de Duque de Caxias, possui unidades fabris em Cabo (PE) e em Triunfo (RS), e sua capacidade de produção atinge 365.000t/ano, incluindo os seguintes produtos: ESBR, borrachas de estireno e butadieno em solução (SSBR), polibutadieno (BR), borracha nitrílica (NBR), borracha termoplástica (TR), polibutadieno líquido (PBLH) e látex de SBR. Possui assim um amplo leque de produtos, comparável ao de grandes companhias como Bayer, Enichem e Goodyear, embora, com capacidade de produção ainda relativamente pequena (Tabela 2). Sua linha de produtos compreende desde commodities até especialidades.

Uma característica marcante da Petroflex é o contínuo investimento em pesquisa e desenvolvimento e na capacitação dos seus pesquisadores, incentivando mestrados e doutoramentos em áreas de interesse da empresa e investindo em infra-estrutura de análise e plantas piloto. Há atividades de pesquisa e desenvolvimento desde o início da operação da companhia e uma área (reportando-se à diretoria) estruturada desde o final da década de 1970. Essas atividades foram mantidas mesmo após a privatização.

Tabela 2

A Petroflex diante dos competidores internacionais

TIPOS DE BORRACHAS FABRICADAS
SSBR ESBR BR NBR EPDM TR CR IR IIR LÁTEX

Capacidade total

1.000 t/ano

\begin{tabular}{r|ccccccccc|c|c|}
\hline Bayer & $x$ & $x$ & $x$ & $x$ & $x$ & & $x$ & $x$ & $x$ & 975 \\
Enichem & $x$ & $x$ & $x$ & $x$ & $x$ & $x$ & $x$ & & $x$ & 884 \\
Goodyear & $x$ & $x$ & $x$ & $x$ & & & & $x$ & & $x$ & 670 \\
\hline PETROFLEX & & & & & & & & & & \\
1992 & & $x$ & & & & & & & $x$ & 220 \\
1998 & $x$ & $x$ & $x$ & $x$ & & $x$ & & & $x$ & 360 \\
\hline
\end{tabular}

Fonte: Elaboração própria dos autores. 
A Tabela 3 apresenta o faturamento e os gastos em P\&D da Petroflex entre 1996 e 2003. Apesar de estável, o valor é pequeno para o setor, e o percentual aplicado em relação às vendas é baixo. Os competidores internacionais vendem mais de US\$1 bilhão anuais e aplicam em média $3 \%$ das vendas em pesquisa e desenvolvimento(COUTINHO et al., 2004).

Tabela 3

Faturamento e dispêndios da Petroflex em $P \& D$

\begin{tabular}{lrrrrrrrr}
\hline & $\mathbf{1 9 9 6}$ & $\mathbf{1 9 9 7}$ & $\mathbf{1 9 9 8}$ & $\mathbf{1 9 9 9}$ & $\mathbf{2 0 0 0}$ & $\mathbf{2 0 0 1}$ & $\mathbf{2 0 0 2}$ & $\mathbf{2 0 0 3}$ \\
\hline $\begin{array}{l}\text { Faturamento líquido } \\
\text { (US\$ milhões }\end{array}$ & 399 & 373 & 300 & 295 & 363 & 325 & 312 & 370 \\
$\begin{array}{l}\text { Dispêndio em P\&D } \\
\begin{array}{l}\text { (US\$ milhões) } \\
\text { Relação (P\&D) / } \\
\text { faturamento (\%) }\end{array}\end{array}$ & 2,6 & 2,5 & 1,8 & 1,7 & 1,9 & 1,6 & 1,6 & 1,9 \\
\hline
\end{tabular}

Fonte: Relatório interno Petroflex.

\section{Resultados da pesquisa: posicionamento tecnológico e nível das competências do setor petroquímico brasileiro e da Petroflex para inovar}

Para avaliar o nível de desenvolvimento das competências e o estágio evolutivo da Petroflex, os resultados obtidos para a empresa são comparados com aqueles levantados para a indústria petroquímica brasileira. No que se refere ao posicionamento tecnológico, das dez empresas pesquisadas na indústria petroquímica, uma se disse imitadora, seis assumiram um posicionamento tecnológico reativo e apenas três admitiram atuar de forma proativa no mercado. As dez empresas respondentes declararam que almejavam evoluir até a posição de proativas. Todas revelaram não ter escala suficiente para gerar os excedentes necessários para realizar pesquisas de caráter fundamental de forma intensiva, característica necessária para almejar o posicionamento de empresa pioneira.

A Tabela 4 apresenta um resumo das entrevistas realizadas com o pessoal da Petroflex. Todos os entrevistados, mesmo aqueles que não trabalhavam nos dois períodos reconheceram uma mudança de postura da empresa. $\mathrm{O}$ que se questiona é quanto ao momento exato dessa mudança, que teria ocorrido entre 1996 e 1998. Para efeito deste estudo, foi considerado o ano de 1997 - quando a empresa começou a produzir borrachas nitrílicas como ponto de mudança da postura tecnológica da empresa, início do processo de diversificação de sua linha de produtos.

Tabela 4

Resumo das entrevistas/características mais relevantes

\begin{tabular}{lll}
\hline & $\mathbf{1 9 9 2 - 1 9 9 7}$ & $\mathbf{1 9 9 7 - 2 0 0 2}$ \\
\hline Postura tecnológica & Imitador & Seguidor reativo \\
\hline Geração da P\&D & Primeira & Segunda \\
\hline Intensidade da P\&D (\%) & Processo (90\%) & Produto (60\%) \\
\hline Tipo de P\&D (\%) & Incremental (95\%) & Incremental (70\%) \\
\hline Modelo de parceria & Compra / licenciamento & $\begin{array}{l}\text { P\&D virtual (universidades e } \\
\text { centros de pesquisa) }\end{array}$ \\
\hline $\begin{array}{l}\text { Modelo de gestão da } \\
\text { produção }\end{array}$ & Automação & $\begin{array}{l}\text { Automação, flexibilidade } \\
\text { operacional, técnicas de gestão }\end{array}$ \\
\hline Marketing & Customização & Diferenciação > Customização \\
\hline Organização & Rígida & Flexível \\
\hline Estratégia & Idéia, em pessoas-chave & Em elaboração \\
\hline
\end{tabular}

Fonte: Elaboração própria a partir das entrevistas e relatórios internos da empresa. 
Uma estrutura organizacional rígida - com pouca integração entre as diversas áreas -, uma atividade de pesquisa e desenvolvimento ainda de primeira geração (ROUSSEL et al., 1991) e a falta de uma estratégia formal disseminada pela companhia levavam a uma inexpressiva capacidade de inovação, o que talvez explique a atuação da empresa como imitadora entre 1992 e 1997. Nesse período, como imitadora e produtora de commodities (mais de $90 \%$ do faturamento no período), a P\&D da empresa voltou-se para desenvolvimentos incrementais de processos e as fábricas investiram maciçamente em automação. O objetivo era reduzir os custos operacionais de produção. Como imitadora, a única parceria desenvolvida no período foi a compra de tecnologias específicas da Japan Synthetic Rubber (JSR). Nesse sentido, há uma certa incoerência entre a produção de commodities e uma customização em larga escala, que chama atenção por um programa de produção voltado para o cliente, implementado naquele período. Entretanto, isso poderia ser explicado pelas próprias características da indústria de polímeros (BOMTEMPO, 1994).

A Tabela 5 apresenta as médias obtidas para o conjunto de competências complexas do setor petroquímico (hoje) e da Petroflex (nos dois períodos avaliados).

$\mathrm{Na}$ determinação das médias apresentadas pelas empresas reativas foram incluídas as notas dadas pela empresa que se posicionou como imitadora. As diferenças encontradas no nível de competências das empresas reativas para as empresas proativas são coerentes com a capacidade de inovação, o que sugere que essas médias poderiam ser utilizadas como um padrão. As empresas reativas poderiam, a partir daí, identificar onde estariam concentradas suas deficiências e desenvolver esforços para superá-las.

A Tabela 6 apresenta as médias obtidas para as competências para inovar, agrupadas conforme a natureza das competências elementares.

Tabela 5

Competências para inovar

(médias agregadas com base nas competências complexas - máximo 5,0)

\begin{tabular}{|c|c|c|c|c|}
\hline \multirow[b]{2}{*}{ COMPETENNCIAS } & \multicolumn{2}{|c|}{$\begin{array}{c}\text { Setor } \\
\text { petroquímico } \\
(2003)\end{array}$} & \multicolumn{2}{|c|}{ PETROFLEX } \\
\hline & 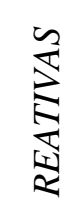 & $\begin{array}{l}\sum^{2} \\
\frac{1}{2} \\
\frac{1}{2}\end{array}$ & 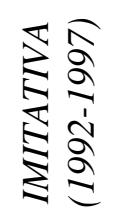 & 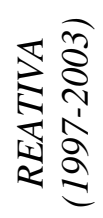 \\
\hline Aplicar a inovação na estratégia de conjunto da empresa & 3,1 & 4,0 & 2,0 & 3,1 \\
\hline Seguir, prever e interferir na evolução dos mercados & 2,3 & 4,4 & 1,4 & 2,3 \\
\hline Desenvolver as inovações & 2,5 & 3,8 & 1,4 & 2,5 \\
\hline Organizar e dirigir a produção de conhecimento & 1,8 & 2,6 & 1,2 & 1,9 \\
\hline Assimilar tecnologias externas & 2,1 & 3,5 & 2,1 & 2,2 \\
\hline Gerir e defender a propriedade intelectual & 1,8 & 3,4 & 1,0 & 1,2 \\
\hline Gerir RH de uma perspectiva inovadora & 2,1 & 2,8 & 1,2 & 1,3 \\
\hline Financiar a inovação & 2,5 & 3,8 & 2,5 & 2,5 \\
\hline Vender a inovação & 2,1 & 3,6 & 1,0 & 1,8 \\
\hline Cooperar para inovar & 2,3 & 3,6 & 1,0 & 1,2 \\
\hline
\end{tabular}

Fonte: Elaboração própria dos autores. 
Tabela 6

Competências para inovar

(médias, segundo a natureza das competências elementares - máximo 5,0)

Setor

petroquímico

(2003)

PETROFLEX

COMPETÊNCIAS

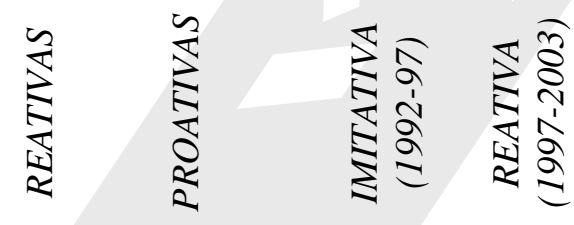

\begin{tabular}{lcccc}
\hline Técnicas & 3,0 & 4,2 & 1,8 & 2,8 \\
\hline Organizacionais & 2,0 & 3,1 & 1,3 & 1,9 \\
Favorecem a criação do conhecimento & 2,2 & 3,0 & 1,2 & 2,1 \\
Favorecem a dimensão transversal & 2,5 & 4,1 & 2,1 & 2,8 \\
Identificam o saber individual e o coletivo & 1,6 & 2,3 & 1,2 & 1,5 \\
\hline Relacionais & 2,2 & 3,9 & 1,4 & 1,9 \\
\hline Meios & 2,1 & 3,4 & 2,0 & 2,1 \\
\hline MÉDIA GERAL & 2,3 & 3,7 & 1,6 & 2,2 \\
\hline
\end{tabular}

Fonte: Elaboração própria dos autores.

As empresas reativas do setor petroquímico apresentam deficiências em termos de competência, seja no âmbito organizacional, quanto no relacional ou no de meios. A média para a identificação do saber individual e do coletivo é particularmente reduzida, mesmo para as empresas proativas. Isso demonstraria pouca preocupação com os recursos humanos por parte das empresas. As competências de meios são insuficientes, principalmente, devido às notórias dificuldades para a realização de pesquisa e desenvolvimento. $O$ nível reduzido das competências de meios comprova a existência de deficiências quanto à formação de alianças e aos diversos aspectos relacionados com a assimilação de tecnologias externas.

A Tabela 7 apresenta a evolução das competências técnicas específicas da Petroflex no período avaliado. Cabe observar que não há consenso quanto ao momento em que as competências utilizadas a partir de 1997 já estariam disponíveis. Assim, para elaborar a figura, a aquisição das competências necessárias para a produção dos novos elastômeros correspondeu à data de lançamento dos mesmos. Alguns dos respondentes, que participaram apenas do período 1992-97, alegaram que parte dessas competências já estavam disponíveis mesmo antes do início da década de 1990. Elas não teriam sido utilizadas antes porque a empresa estava impedida de buscar uma maior diversificação. Como uma estatal, a Petroflex tinha de seguir o planejamento estabelecido pelo governo para o setor petroquímico, o que restringia sua liberdade para produzir outros elastômeros. Como alguns desses técnicos participaram do processo de aquisição e transferência de tecnologia para outras empresas (também estatais) de elastômeros do setor, é razoável supor que essas competências, pelo menos em parte, já existissem na companhia.

É preciso reconhecer ainda que os técnicos que permaneceram na empresa depois de 1997 tinham grande experiência acumulada nos processos existentes. Além disso, conforme pode ser visto na Tabela 7, os novos produtos tinham características de processo bastante similares com o daqueles já em produção. Isso requeria o desenvolvimento de aspectos específicos, que muitas vezes demandavam conhecimentos básicos de que a companhia já dispunha. Cabe lembrar que, à exceção das borrachas moídas, dos compostos e das borrachas acrílicas, todos os outros produtos desenvolvidos a partir de 1997 ocuparam plataformas industriais existentes, o que confirma a idéia de similaridade entre os processos empregados. Apenas a combinação desses fatores poderia explicar o sucesso e a rapidez com que os produtos foram desenvolvidos nessa época. 
Nesse sentido, em face do exposto, pode-se admitir que o não desenvolvimento anterior desses produtos poderia ser atribuído à inexistência das competências de implementação de natureza organizacional e relacional. Isso estaria de acordo com a posição evolutiva imitadora até 1997, reconhecida por todos os respondentes. 
- 2

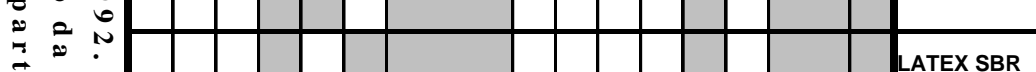

$\because 2$

$2 \mathrm{~B}$

$\odot \tau$

:

$\infty$

$\infty$

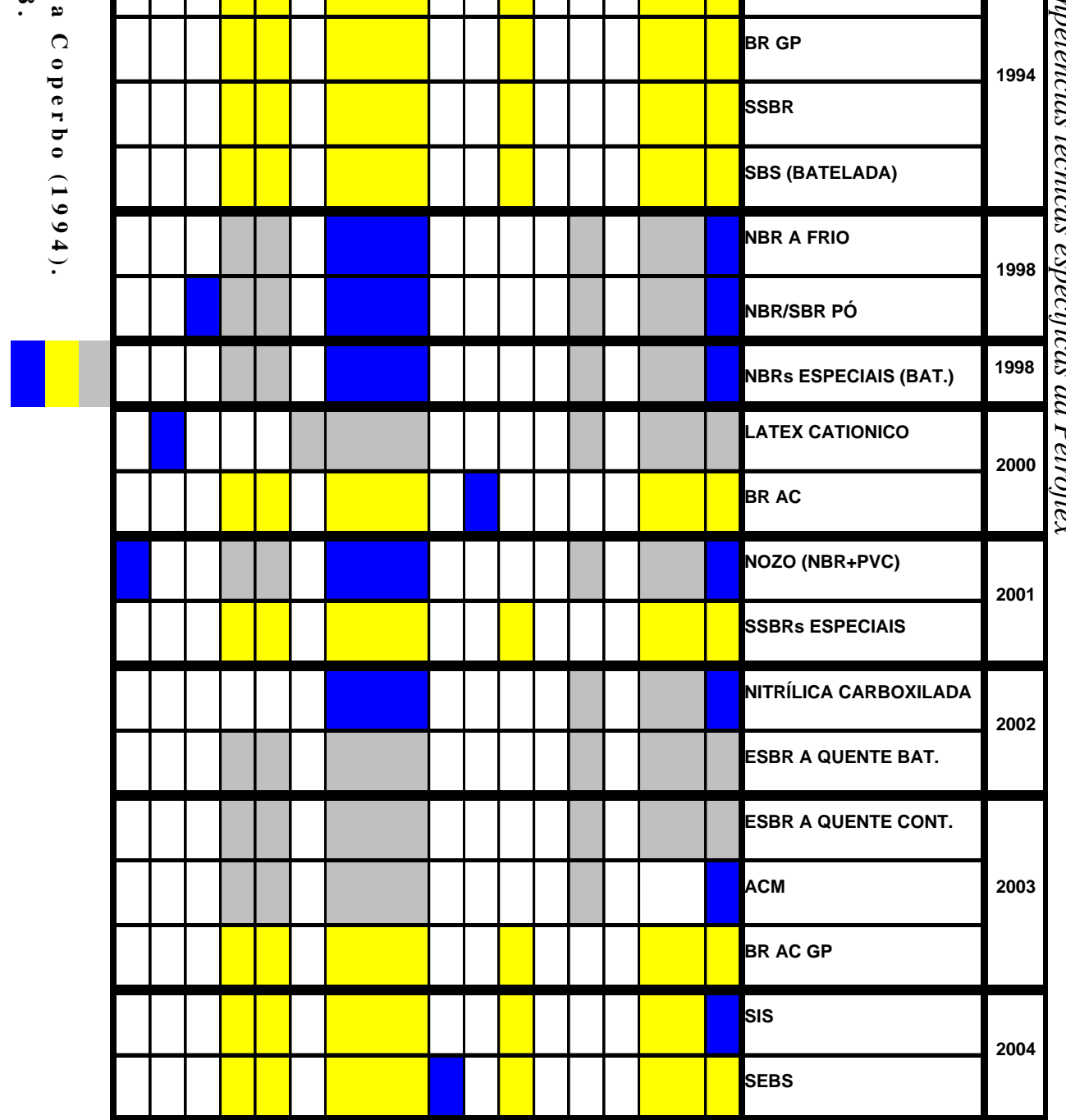




\section{Análise dos resultados: a evolução da Petroflex em termos de posicionamento tecnológico e competências para inovar}

Embora a Petroflex não tenha desenvolvido uma estratégia formal, ou mesmo coordenada, é possível reconhecer, a partir da análise do material apresentado na seção anterior, que havia algum grau de emergência de estratégia. Entre 1992 e 1997, diante da concorrência, a empresa procurou reduzir custos a partir da automação e da redução do seu passivo tecnológico de processo. Aparentemente, isso não foi suficiente e ela teve que diversificar.

A partir de 1997, a Petroflex diversificou seu portfólio, atuando como seguidora, "copiando" produtos já existentes nos mercados nacional e internacional. Isso parece comprovar a idéia de Mintzberg \& Quinn (2001) de que a estratégia muitas vezes não é planejada, mas que surge a partir de um padrão de decisões tomadas no dia-a-dia da empresa.

Adiante, são analisadas as evoluções das competências técnicas específicas e das competências de identificação e implementação (competências técnicas gerais, organizacionais, de meios e relacionais). São mostrados indicadores que possam corroborar a evolução identificada pelas notas obtidas na aplicação do questionário "competências".

\subsection{Evolução das competências técnicas específicas}

O Tabela 7 demonstrou como evoluíram as competências específicas da empresa. Sempre tomando como base o conhecimento já existente, foram desenvolvidas e lançadas diversas novas famílias de produto. Assim, os conhecimentos no processo de polimerização em emulsão levaram a seis novas famílias de produtos (NBR, borrachas moídas, látex catiônico, látex carboxilado, ESBR a quente e ACM). Da mesma forma, o conhecimento do processo de polimerização em solução levou à agregação de quatro novas famílias (BR alto cis, SSBRs funcionalizados, SIS e Sebs) ao portfólio da empresa.

O número de produtos disponibilizados para o mercado (Figura 2) é um indicador capaz de comprovar a evolução da capacidade técnica específica de uma empresa.

Figura 2

Evolução dos produtos disponíveis para o mercado

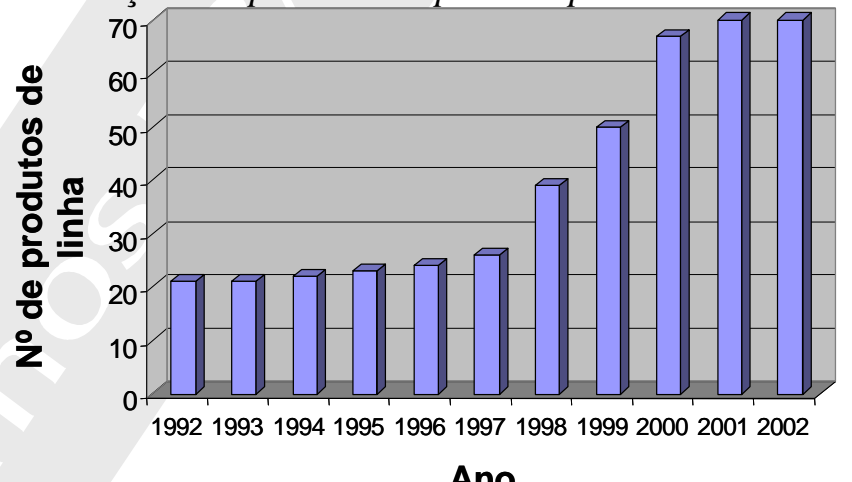

Fonte: Elaboração própria.

\subsection{Evolução das competências de identificação/implementação}

Há uma clara evolução da Petroflex que, nos períodos analisados, sai de uma média geral de 1,6 para 2,2 (Tabela 6). Esse último valor é condizente com o encontrado $(2,3)$ para o nível de competências gerais das empresas reativas do setor petroquímico brasileiro. O indicador utilizado na seção anterior (disponibilização de produtos para o mercado) é válido para comprovar a evolução na capacidade de identificação e de 
implementação. Como todos os produtos lançados já existiam no mercado, fica caracterizada a atuação de uma empresa reativa e a inexistência de um nível de competências gerais que possa garantir uma atuação proativa.

\subsubsection{Evolução das competências técnicas}

A melhoria nos indicadores de competência técnica (Tabela 8) comprova a evolução nas competências de: controle da qualidade e eficácia de produção $(3,5 / 4,3)$, avaliação de seus processos em termos tecnológicos $(2,3 / 3,1)$ e busca de novos formatos organizacionais mais adequados às necessidades de mercado $(2,0 / 3,3)$. Nesse último caso, cabe citar a implantação das estações de trabalho e as mudanças feitas na área comercial a partir de 2002. As fábricas foram divididas em estações de trabalho, cada qual atuando como uma "fábrica independente", com metas e objetivos específicos. Na área comercial, foram criadas novas gerências e a atuação passou a se basear em segmentos de mercado e não mais em produtos, o que aumentou a aproximação e a eficiência no trato com os clientes.

A empresa ainda é lenta na aquisição de equipamentos $(1,0 / 2,5)$ e insumos tecnologicamente novos $(1,9 / 2,3)$, no monitoramento tecnológico $(1,3 / 1,8)$ e na avaliação das tecnologias externas $(0,9 / 2,1)$. É possível afirmar que parte das reduções de custos (fixo e variável) provêm de novas matérias-primas e da automação, o que explicaria a evolução dessas competências. A empresa deverá criar uma área específica ou, pelo menos, colocar profissionais atuando de forma sistemática na área de monitoramento e avaliação de tecnologias externas, se quiser evoluir para uma atuação proativa no mercado.

\section{Tabela 8}

Indicadores de evolução das competências técnicas

\begin{tabular}{lrrr}
\hline & $\mathbf{1 9 9 2}$ & $\mathbf{1 9 9 7}$ & $\mathbf{2 0 0 2}$ \\
\hline Material fora de especificações (\%) & 4 & 1,8 & 0,8 \\
\hline Produção entre reclamações (t) & ND & 1800 & 3000 \\
\hline Passivo ambiental (1000t) & 24 & 37 & 0 \\
\hline Custo fixo total (US\$ milhões) & 86 & 91 & 42 \\
\hline Custo fixo unitário (US\$/t) & 467 & 284 & 130 \\
\hline Custo variável (1992=100\%) & 100 & 93 & 89 \\
\hline
\end{tabular}

Fonte: Relatórios internos Petroflex

\subsubsection{Evolução das competências organizacionais}

Houve uma evolução no nível de competências organizacionais $(1,3 / 1,9)$ compatível com a mudança no posicionamento tecnológico de empresa imitadora para reativa (nível médio na indústria: 2,0). $\mathrm{O}$ desenvolvimento dessas competências parece ser o maior desafio para que a empresa venha a atuar como proativa (nível médio na indústria: 3,1). Essas competências têm forte ligação com a "cultura" da empresa e por esse motivo demandam um esforço maior para que se transformem, exigindo iniciativas e um forte apoio da alta administração. As competências organizacionais são estudadas segundo três grupos particulares:

\section{- Competências organizacionais que favorecem a criação do conhecimento}

Houve uma forte evolução nas competências que buscam favorecer o trabalho em equipe $(1,9 / 2,9)$, incentivar a formulação de novas idéias $(2,0 / 3,4)$ e a autonomia individual $(2,4 / 3,4)$. Essa evolução é comprovada com base na atuação das estações de trabalho e na tentativa de integração entre as áreas, através da promoção de encontros, cursos e mesmo por alguns procedimentos de trabalho em que diferentes áreas trabalham juntas.

No entanto, verifica-se que, apesar de alguma evolução, as competências de valorização da criatividade na avaliação individual $(1,3 / 2,3)$, aceitação de comportamentos criativos não diretamente produtivos $(1,1 / 1,6)$, premiação das idéias implantadas $(0,8 / 0,9)$ e promoção do compartilhamento do conhecimento $(0,6 / 1,9)$ ainda são claramente deficientes. A partir dos questionários e entrevistas, verificou-se que não existem programas que incentivem compartilhar o conhecimento, que a empresa de uma forma geral não premia as idéias originais quando adotadas (estaria surgindo em 2004 um programa nesse sentido) e atribui um peso pequeno à 
originalidade e à criatividade na avaliação individual (na verdade, a empresa parece carecer de um real sistema de avaliação individual).

A empresa não procurar motivar de forma sistemática os que têm conhecimentos estratégicos $(0,8 / 1,1)$, nem tem mecanismos que garantam a preservação do conhecimento estratégico em caso de perda de um profissional $(0,5 / 1,1)$. De modo geral, a empresa parece desconhecer os que tem conhecimento estratégico. Isso explicaria o baixo nível das competências em questão.

\section{- Competências organizacionais que favorecem a dimensão transversal}

Com a adoção do BSC (balanced scorecard), a empresa vem procurando promover a disseminação de uma visão global de suas atividades e negócios entre os empregados $(1,8 / 3,0)$. Embora já venha procurando se estruturar melhor em torno de seus projetos de inovação $(1,0 / 1,9)$ e procure integrar todas as áreas afins desde $o$ início dos mesmos (1,3/2,1), as notas obtidas no período 1997-2002 ainda não expressam esse esforço. Parece que, mesmo com a existência de alguns procedimentos, haveria ainda uma certa dificuldade de trabalho em conjunto.

\section{- Competências organizacionais que identificam o saber individual e o coletivo}

A empresa não mapeia as competências de pessoal $(0,8 / 1,9)$, não avalia a produção coletiva de conhecimento em relação aos concorrentes $(0,6 / 1,3)$ e não avalia a contribuição individual $(1,0 / 1,4)$, o que responderia pela baixa evolução dessa competência no período.

Apesar de já começar a identificar o chamado know how estratégico $(1,5 / 1,9)$, a empresa ainda se ressente de um processo sistemático que garanta a efetividade e a continuidade do processo.

Há um gap muito forte na complexa competência "gerir os recursos humanos de uma perspectiva de inovação" $(1,2 / 1,3)$, mesmo quando comparada com a média das empresas reativas do setor $(2,1)$. Nesse ponto, as regras de mobilidade $(0,8 / 1,1)$ e recompensa $(1,4 / 1,5)$ são pouco transparentes. Não existe uma avaliação da influência exercida pela formação na inovação $(0,7 / 1,1)$. Verifica-se que elas não evoluíram no período. Esta seria uma das competências em que a empresa deveria colocar o maior esforço para desenvolvimento.

\section{- Outras competências organizacionais}

Há uma clara deficiência no tratamento dos aspectos relacionados à propriedade intelectual. Muito deve ser melhorado na identificação $(1,4 / 5,0)$, na proteção $(1,5 / 5,0)$ e na manutenção $(1,2 / 5,0)$ dos conhecimentos estratégicos. Quanto à capacidade de "gestão dos recursos humanos de uma perspectiva de inovação", praticamente, não houve evolução no período $(1,2$ para $1,3 / 5,0)$. Parece que a empresa ainda não está preparada para identificar necessidades emergentes ou comportamentos de consumo pioneiros no mercado $(1,5 / 1,1)$.

\subsubsection{Evolução das competências de meios}

Embora realize pesquisa e desenvolvimento $(3,3 / 3,4)$, a diferença para a nota correspondente a esse item das empresas proativas (média do setor: 4,3) talvez possa ser explicada pelo nível de esforço despendido. A Petroflex aplica entre 0,5 e $0,8 \%$ do seu faturamento em P\&D, contra $2,5 \%$ a $3,0 \%$ de seus principais concorrentes no mercado. Deve-se considerar ainda que estes possuem uma base de faturamento também superior. O baixo nível de contratação externa de pesquisa e desenvolvimento $(2,1 / 2,5)$ parece estar em desacordo com as diversas parcerias com institutos públicos de pesquisa. Contudo, é preciso prestar atentar ao fato de que as parcerias com as universidades estão centradas em projetos de pesquisa fundamentais ou na simples realização de análises. Quase todas as pesquisas de curto/médio prazo são feitas internamente.

A Petroflex não parece se interessar pela captação de profissionais de alta qualificação. Talvez, pelos resultados obtidos entre 1997 e 2003, a empresa considere que já tenha esses profissionais para as áreas de processo e produto. No entanto, a área de desenvolvimento de novas aplicações, com sua dinâmica e requisitos próprios, parece ainda bastante carente. 
Quanto à contratação de tecnologia, apenas uma ocorreu desde 1992, que foi a da JSR. Isso explicaria o baixo índice dessa competência $(2,0 / 1,9)$. No entanto, cabe observar que a empresa procurou algumas empresas para licenciar tecnologias específicas. Em todos os casos, o licenciamento lhe foi negado.

Não houve qualquer evolução quanto às competências relativas a "financiar a inovação". Não houve evolução nas notas médias dos quesitos "conhecer" $(3,3 / 3,4)$ e "manter contato" $(3,1 / 3,2)$ com as fontes de financiamento privados e públicos. As empresas proativas, com uma nota superior a 4,0 nos dois quesitos, manteriam e buscariam de maneira bem mais sistemática o fomento a sua atividade de inovação. Da mesma forma, verificase que a empresa não evoluiu nas competências relacionadas a avaliar antecipadamente $(2,1 / 2,2)$ e a "posteriori" (1,4/1,5), de forma sistemática, o conjunto de custos ligados à inovação. Isso estaria mudando. Procedimento para seleção de projetos de P\&D e indicadores no balanced scorecard parecem indicar que a empresa deverá evoluir de forma substantiva nessa competência, ainda no curto prazo.

As competências para "vender a inovação" (integralmente contida nas competências de meios) cresceram $(1,0 / 1,8)$. Esse crescimento decorreu da própria mudança do foco da empresa, de processo para produto. No entanto, essas competências estariam muito longe do nível exigido para empresas proativas (média do setor: 3,6). Nesse sentido, a criação de uma área formal de marketing a partir de 2002 deverá acelerar o processo de desenvolvimento dessas competências.

Pode-se questionar quanto à importância da competência "vender a inovação" para empresas do setor petroquímico que vendem principalmente commodities. No entanto, como a empresa deseja adotar uma postura proativa na venda de produtos baseados em performance, tal competência parece ser de grande importância. $\mathrm{O}$ desenvolvimento da marca e o estabelecimento da empresa no mercado como inovadora deverá facilitar a colocação desses produtos em segmentos conservadores ou de maior poder mercadológico.

\subsubsection{Evolução das competências relacionais}

A maior interação com o mercado é o ponto marcante na passagem de uma estratégia de empresa imitadora para seguidora reativa. A empresa passa a observar melhor os concorrentes (produtos são avaliados, discute-se a implantação de uma inteligência competitiva e planos de negócio consideram a atuação dos mesmos), os clientes (mercado segmentado, prevê-se a implantação de uma pesquisa de satisfação) e mesmo os clientes dos clientes. Embora a Petroflex já venha trabalhando (em parte) a concorrência e os clientes, o conhecimento a respeito das necessidades dos clientes dos seus clientes ainda é limitado e não há qualquer programa para ampliá-lo. Assim, os baixos valores das competências para seguir, prever e atuar sobre a evolução dos mercados (competência complexa integralmente contida na competência de base relacional) demonstram a dificuldade para se antecipar às necessidades do mercado. A empresa se volta quase que exclusivamente para o dia-a-dia do mercado, não se preparando para eventuais rupturas.

Apesar da forte intenção de estabelecer parcerias com fornecedores e clientes, a empresa ainda não conseguiu estabelecer relacionamentos que levem a efetivas parcerias para inovação. Com isso, as notas permanecem reduzidas, tanto para as parcerias com fornecedores $(1,5 / 1,2)$ quanto para aquelas com clientes $(1,6 / 2,3)$. Não havia parcerias com concorrentes em nenhum dos períodos avaliados $(0,1 / 0,2)$. A evolução dos contratos para desenvolvimento conjunto poderia ser um indicador. Apesar de alguns trabalhos realizados, até hoje a Petroflex não assinou qualquer contrato nesse sentido, o que indica um baixo nível de evolução da competência "cooperar para inovar".

A já existente cooperação com institutos públicos de pesquisa e desenvolvimento cresceu ao nível de empresas proativas (Tabela 9), o que comprova a evolução dessa competência $(3,1 / 3,6)$ na empresa. Agora, a empresa começa a discutir a necessidade de implementação da chamada pesquisa e desenvolvimento de quarta geração, no sentido atribuído por Miller \& Morris (1999). Isso deverá permitir uma melhora na identificação de oportunidades, um aumento na capacitação em aplicação e a melhoria da imagem da empresa. 
Tabela 9

Parcerias realizadas

\begin{tabular}{|c|c|c|}
\hline PERÍODO & INSTITUIÇÃO & PROJETO / OBJETIVOS DA PARCERIA \\
\hline \multirow{3}{*}{ 1992-1997 } & IQ/UFRJ & Serviços de análise \\
\hline & IPT & Uso de TR na modificação de asfalto \\
\hline & Cenpes/Petrobras & Desenvolvimento de tecnologia de acoplamento (TR radiais) \\
\hline \multirow{9}{*}{ 1997-2002 } & IQ/UFRGS & $\begin{array}{l}\text { - Desenvolvimento de processo para hidrogenação de TRs } \\
\text { via catalisadores metalocênicos (1996-1999); } \\
\text { - Desenvolvimento de processo para hidrogenação de } \\
\text { borrachas nitrílicas (1998-2000); } \\
\text { - Desenvolvimento de processo para obtenção de } \\
\text { polietilenos elastoméricos (2000-2001); }\end{array}$ \\
\hline & IQ/Uerj & $\begin{array}{l}\text { Avaliação de componentes para o catalisador de Nd utilizado } \\
\text { na produção de BR-AC (2001-2003); }\end{array}$ \\
\hline & IMA/UFRJ & $\begin{array}{l}\text { - Alunos em tese de mestrado/doutorado (próprios e } \\
\text { concessão de bolsa); } \\
\text { - Serviços de análise e avaliação de materiais; }\end{array}$ \\
\hline & IQ/UFRJ & Serviços de análise e avaliação de materiais; \\
\hline & EQ/UFRJ & $\begin{array}{l}\text { - Serviço de prospecção tecnológica (levantamento e aná- } \\
\text { lise de patentes) entre } 2000 \text { e } 2001 \text {; } \\
\text { - Análise da concorrência (2001); } \\
\text { - Alunos com tese de mestrado/doutorado (próprio e con- } \\
\text { cessão de bolsa) }\end{array}$ \\
\hline & INT & Serviços de análise e avaliação de materiais (2001); \\
\hline & $\begin{array}{l}\text { Programa de } \\
\text { Engenharia } \\
\text { Química } \\
\text { (Coppe/UFRJ) }\end{array}$ & $\begin{array}{l}\text { Incentivo e bolsas de mestrado e doutorado na área de } \\
\text { tratamento de rejeitos e meio ambiente; }\end{array}$ \\
\hline & $\begin{array}{l}\text { Universidade } \\
\text { Akron (EUA) }\end{array}$ & Participação em projeto de cooperação tecnológica \\
\hline & IPT & Uso de borracha termoplástica na modificação de poliestireno \\
\hline
\end{tabular}

Fonte: Elaboração própria a partir de relatórios internos da empresa.

A busca de parcerias com concorrentes em áreas de pesquisa básica poderia ajudar a empresa a se preparar para inovações radicais no mercado, a um custo reduzido. Poderia envolver o estabelecimento de consórcios com a participação de centros de pesquisa e universidades direcionados para pesquisa fundamental.

\section{Conclusões}

Este artigo propõe uma metodologia para avaliar as competências de uma empresa para a inovação. Com base em uma análise longitudinal, foi possível avaliar o grau de evolução dessas competências ao longo do tempo e suas relações com a postura tecnológica adotada por uma empresa petroquímica brasileira; no caso, a Petroflex Indústria e Comércio S.A. A associação com a postura tecnológica desejada permite que a empresa identifique as competências a serem desenvolvidas. A metodologia aqui adotada parece merecer outros testes, podendo ser aprimorada e tornar-se um recurso gerencial para estratégias de inovação.

Ainda no campo metodológico, o estudo procura ampliar o escopo das competências para inovar, propostas por François et al. (1999), de uma perspectiva das competências gerais, comuns a todas as empresas inovadoras, incorporando um grupo de competências específicas à firma e à indústria. Essas competências são intimamente relacionadas com os conhecimentos em produtos e processos da empresa. Parece-nos que ao levar em 
consideração essas competências técnicas específicas em estreita relação com as competências gerais, de identificação e de implementação, maiores são as possibilidades de se tirar lições práticas dessa abordagem.

Seguem-se as conclusões específicas deste estudo, em relação à Petroflex. O entendimento é o de que o aumento na capacidade de adaptação e transformação da empresa ficou evidenciado a partir das mudanças organizacionais (estações de trabalho e segmentação da área comercial), na melhoria dos índices de produção e no lançamento de novos produtos no período 1997-2003. No entanto, a anunciada intenção de vir a atuar como seguidora proativa exigirá da empresa desempenho superior nos aspectos técnicos, bem como o estabelecimento de uma forma sistemática de identificação e mensuração das competências internas.

Com as diversas certificações obtidas, pode-se afirmar que os procedimentos e práticas existentes na empresa estão hoje documentados e disponíveis para todos. A criação das estações de trabalho leva a uma maior responsabilidade e a partir daí, promove e valoriza a criatividade no nível do chão-de-fábrica. Contudo, a empresa parece não considerar a necessidade de incentivar a criação e o compartilhamento do conhecimento tácito em níveis organizacionais intermediários e, mesmo, de média gerência. Dessa forma, é possível afirmar que há uma certa dificuldade na conversão do conhecimento tácito em explícito, processo necessário para que o conhecimento flua, se desenvolva e se perpetue na empresa (NONAKA \& TAKEUCHI, 1995).

Para evoluir, a empresa deverá implantar um processo de avaliação individual, além de um sistema de reconhecimento pelo qual a criatividade e o empreendedorismo sejam identificados e premiados. Deve ainda passar a aceitar e permitir o desenvolvimento de comportamentos criativos não diretamente produtivos. Essas iniciativas são fundamentais para que surjam novas competências, tanto de caráter técnico específico, como organizacional e relacional.

É verificado também que ainda não existe um processo formal de prospecção e identificação tecnológica (banco de idéias), nem de seleção de oportunidades (metodologia e padrões definidos). Isso evidenciaria uma falta de preparo para enfrentar o futuro, o que fica evidenciado no planejamento estratégico da empresa. Embora este cubra o período 2002-07, só há previsão de lançamento de produtos até 2005.

Supondo que as competências técnicas específicas já existissem antes de 1997 e que nessa época ainda não havia uma estratégia formal definida, é possível inferir que foram os grupos de empreendedores que iniciaram o processo de desenvolvimento de novos produtos. Nesse caso, a base organizacional e relacional criada a partir dos processos de certificação e a recente implantação das estações de trabalho permitiram a evolução das competências de identificação e implementação, garantindo o sucesso desses empreendedores internos.

Sintetizando o perfil das competências da Petroflex, sugere-se que apenas suas competências técnicas se aproximam de um nível satisfatório mínimo, o que parece ter sido comprovado pela capacidade de geração de novos produtos verificada nos últimos anos. Mesmo assim, as competências organizacionais ainda são deficientes. Embora a empresa tenha sido capaz de trabalhar de forma efetiva sua estrutura organizacional (estações de trabalhos e segmentação da área comercial), ainda existe um grande campo de desenvolvimento na área de recursos humanos (incentivos à criatividade e à inovação, identificação dos elementos e das competências-chave, mobilidade, transparência etc.), de modo a construir os mecanismos organizacionais necessários à criação do novo conhecimento, no sentido evidenciado por Nonaka \& Takeuchi (1995) e Leonard-Barton (1995). 


\section{Referências bibliográficas}

ADLER, P. S. Technology strategy: a guide to the literature. Research on Technological Innovation, Management and Policy, JAI Press Inc., n.4, p.25-151, 1989.

BARNEY J. Gaining and sustaining competitive advantage. Addison-Wesley, 1996.

BOM TEM PO, J. V. Innovation et organisation: le cas de I 'industrie des polymère. Tese (Doutorado em economia industrial) - Cerna/Ecole des Mines de Paris, 1994.

BURGELMAN, R. A.; MAIDIQUE, M. A.; WHEELWRIGHT, S. C. Strategic Management of Technology and Innovation. Irwin, EUA: Mcgraw Hill, 1995.

CHIESA, V., M ANZINI, R. Towards a framework for dynamic technology strategy. Technology Analysis \& Strategic Management, v.10, n.1, p.111-129, 1998.

COLLIS, D. J.; MONTGOMERY, C. A. Competing on resources: strategy in the 1990's. Harvard Business Review, p.118-128, July/Aug. 1995.

COUTINHO, P. L. Estratégia tecnológica e gestão da inovação: uma estrutura analítica voltada para os administradores das empresas Tese (Doutorado) Escola de Química - Universidade Federal do Rio de Janeiro (UFRJ), Rio de Janeiro, 2004.

; BOM TEM PO, J. V.; WEINBERG, G. New typology for the strategi /technological positioning of firms in developing countries. Latin Ämerican Business Review, v.5, n.1, p.95-117, Oct. 2004.

FOSTER, R. Inovação, a vantagem do atacante. São Paulo: Best Seller, 1986.

FRANCOIS, J.-P. et al. Décrire les compétences pour l'innovation: une proposition d'enquête, In: FORAY D.,MAIRESSE J. (Ed.). Innovations et performances, approches interdisciplinaires. Éditions Ehess, 1999.

FROHM AN, A. L. Putting technology into strategic planing. California Management Review, v.27, n.2, p.48-59, 1985.

GRIFFIN, A. Modelling and measuring product development cycle time across industries. Journal Engineering Technology Management, V.14, p.1-24, 1997.

HAMEL G.; PRAHALAD C. K. The core competence of the corporation. Harvard Businness Review, v.68, n.3, p.79-91, 1990.

Competindo pelo futuro. Rio de Janeiro: Campus, 1995.

KIM, L. Building technological capability for industrialization: analytical frameworks and Korea experience. Industrial and Corporate Change, v.8, n.1, Mar. 1999.

LEONARD-BARTON, D. Wellsprings of knowledge: building and sustaining the sources of innovation. Harvard Business School Press, 1995.

MAIDIQUE, M. A.; PATCH, P. Corporate strategy and technology policy. In: TUSHMANT, M. L.; MOORE, W. L. Readings in the management of inovation. 2. ed. Cambridge, MA: Ballinger, 1988. p.236-248.

MALERBA, F.; ORSENIGO, L. Technological regims and firm behavior. Industrial and Corporate Change, n.2, p.45- 71, 1993.

MILLER, A. A taxonomy of technological settings, with related strategies and performance levels. Strategic Management Journal, n.9, p.239-254, 1988.

MILLER, W. L.; MORRIS, L. Fourth generation R\&D. J ohn Wiley \& Sons, Inc., 1999.

MINTZBERG, H.; QUINN, J. B. 0 processo de estratégia. Porto Alegre: Bookman, 2001.

MORONE, J. Technology and competitive advantage - the role of general management. Research Technology Management, p.16-25, Mar./Apr. 1993.

MUNIER F. Taille de la firme et innovation: approches théoriques et empiriques fondées sur le concept de compétence, Thèse (doctorat en sciences économiques) - Université Louis Pasteur, Estrasburgo, 1999.

NELSON R.; WINTER S. An evolutionary theory of economic change. Cambridge: Harvard University Press, 1982.

NONAKA I.; TAKEUCHI H. The knowledge-creating company. Oxford: Oxford University Press, 1995.

PAVITTK. What we know about the strategic management of technology. California Managemente Review, p.17-26, spring, 1990.

; ROBSON, M.; TOWSEND, J. Technological accumulation, diversification and organization in UK companies, 1945- 1983. Management Science, v.35, n.1, 1989.

PENROSE, E. The theory of the growth of the firm. New York: J ohn Wiley, 1959.

PRAHALAD, C. K., Managing Discontinuities: the emerging challenges, Research Technology Management, p. 14-22, maio-junho, 1998.

ROUSSEL, P. A.; SAAD, K. N.; BOHLIN, N. Third generation R\&D. Arthur D. Little Inc.; Harvard Business School Press, 1991. 
TEECE, D.; PISANO, G.; SHUEN, A.. Dynamic capabilities and strategic management. Strategic Management Journal, v.18,n.7, p.509-533, 1997.

WERNERFELT, B. A resource- based view of the firm. Strategic Management Journal, v.5, n.2, p.171-180, 1984. 


\section{Anexo 1}

\section{Questionário: competências para inovar}

Dar notas de 0 a 5, conforme o grau de desenvolvimento da competência na sua empresa (5 quando a competência já estiver plenamente desenvolvida):

1. Sua empresa controla a qualidade e a eficácia da produção?

2. Sua empresa faz um balanço tecnológico de seus processos?

3. Sua empresa avalia novos formatos organizacionais?

4. Sua empresa faz um levantamento das competências do pessoal?

5. Sua empresa procura dar aos empregados uma visão global de suas atividades e negócios?

6. Sua empresa analisa os produtos concorrentes?

7. Sua empresa analisa as patentes dos seus concorrentes?

8. Sua empresa analisa as publicações dos profissionais dos concorrentes?

9. Sua empresa analisa a segmentação e as necessidades da clientela?

10. Sua empresa procura conhecer junto ao serviço pós-venda ou com os distribuidores as reações da clientela?

11. Sua empresa tem conhecimentos sobre as necessidades dos clientes dos seus clientes?

12. Sua empresa identifica as necessidades emergentes ou os comportamentos de consumo pioneiros?

13. Sua empresa se estrutura em torno de seus projetos de inovação?

14. Sua empresa coloca todas as áreas afins ( $\mathrm{P} \& \mathrm{D}$, marketing, industrial etc.) nos projetos desde o seu início?

15. Sua empresa favorece o trabalho em equipe para inovar?

16. Sua empresa favorece a mobilidade entre os serviços para inovar?

17. Sua empresa identifica os novos produtos colocados no mercado pelos seus fornecedores?

18. Sua empresa adquire rapidamente os equipamentos tecnologicamente novos?

19. Sua empresa adquire rapidamente os insumos tecnologicamente novos?

20. Sua empresa incentiva a formulação de novas idéias?

21. Sua empresa deixa um certo grau de autonomia a cada um para inovar?

22. Sua empresa valoriza na avaliação individual a originalidade e a criatividade própria?

23. Sua empresa aceita comportamentos criativos não diretamente produtivos?

24. Sua empresa premia as idéias originais quando elas são adotadas?

25. Sua empresa promove um compartilhamento do conhecimento?

26. Sua empresa avalia a sua produção coletiva de conhecimento em relação aos concorrentes da empresa?

27. Sua empresa avalia a contribuição de cada um à produção do conhecimento?

28. Sua empresa conhece as tecnologias dos concorrentes?

29. Sua empresa conhece as tecnologias do futuro (monitoramento tecnológico)?

30. Sua empresa avalia/testa as tecnologias externas?

31. Sua empresa faz pesquisa e desenvolvimento?

32. Sua empresa subcontrata pesquisa e desenvolvimento?

33. Sua empresa tem um departamento específico para pesquisa e desenvolvimento?

34. Sua empresa faz pesquisa e desenvolvimento em cooperação com institutos públicos de pesquisa e desenvolvimento?

35. Sua empresa utiliza invenções de terceiros (patentes, licenças)?

36. Sua empresa contrata empregados de alta qualificação científica para inovar?

37. Sua empresa compra empresas, no todo ou em parte, para inovar?

38. Sua empresa participa de joint ventures, alianças estratégicas e outras formas de cooperação para inovar? 
39. Sua empresa decide depositar (ou não) um título de propriedade intelectual em função do benefício global da empresa?

40. Sua empresa incorpora o risco de cópia e imitação desde a concepção do produto?

41. Sua empresa vigia a existência e a difusão das cópias e imitações?

42. Sua empresa combate na justiça a cópia e a imitação?

43. Sua empresa atua de modo a desvalorizar junto aos clientes as cópias e imitações?

44. Sua empresa identifica os seus conhecimentos e know how estratégicos?

45. Sua empresa identifica as pessoas que detêm os conhecimentos estratégicos?

46. Sua empresa sensibiliza o pessoal quanto ao caráter estratégico e confidencial de seus conhecimentos?

47. Sua empresa controla a comunicação sobre os conhecimentos estratégicos?

48. Sua empresa motiva especialmente as pessoas detentoras dos conhecimentos estratégicos (remunerações, carreiras)?

49. Sua empresa garante em caso da saída de um profissional, a conservação pela empresa do máximo de conhecimento estratégico?

50. Sua empresa localiza os especialistas atuais e do futuro no mercado?

51. Sua empresa avalia, na contratação, a propensão a inovar?

52. Sua empresa avalia, na contratação, a capacidade de trabalhar em equipe?

53. Sua empresa deixa transparente a avaliação de cada um e a recompensa dos melhores?

54. Sua empresa deixa transparentes as regras de mobilidade?

55. Sua empresa avalia as necessidades de formação de cada um?

56. Sua empresa sensibiliza cada um a pedir e escolher uma formação adaptada?

57. Sua empresa avalia as repercussões da formação na inovação?

58. Sua empresa avalia antecipadamente o conjunto de custos ligados à inovação?

59. Sua empresa avalia a posteriori os custos de inovações antigas?

60. Sua empresa conhece os modos de financiamento privados e públicos da inovação?

61. Sua empresa se comunica habitualmente com financiadores potenciais da inovação?

62. Sua empresa tem uma estratégia de oferta promocional específica para produto novo?

63. Sua empresa determina o alvo, a mídia e o tipo de mensagem da publicidade para o produto novo?

64. Sua empresa procura dar uma imagem "inovadora e de vanguarda" da empresa (instalações, comunicação, documentos publicados)?

65. Sua empresa realiza inovações em cooperação com seus concorrentes?

66. Sua empresa realiza inovações em cooperação com empresas fornecedoras?

67. Sua empresa realiza inovações em cooperação com empresas usuárias dos seus produtos?

Em geral, é a sua empresa que toma a iniciativa de buscar parceiros para o desenvolvimento de novos produtos? 